\title{
An Investigation into the Factors that Determine Successful Succession Planning in Small to Medium-Sized Family-Owned Businesses in Johannesburg, South Africa
}

\author{
Suzette Claase, Dr Rishaad Ebrahim* \\ MANCOSA Graduate School of Business, 16 Samora Machel St, Durban Central, Durban, 4001, South Africa \\ *Corresponding Author: Dr Rishaad Ebrahim, MANCOSA Graduate School of Business, 16 Samora \\ Machel St, Durban Central, Durban, 4001, South Africa
}

\begin{abstract}
Lack of succession or leadership planning may result in leaving an organisation in turmoil, with employees becoming uncooperative if the new candidate is unaware of the current corporate culture. In any country, the small to medium-sized, family-owned businesses, contribute a fair amount of revenue to the economy, and it would be advantageous if these organisations could succeed over a number of generations. Just as any larger organisation, it is of great importance to investigate what and if any succession planning is being practiced in these medium-sized companies. For the purpose of this study, a qualitative approach was deemed appropriate. The researcher could obtain a deeper understanding concerning the psychology and rationale behind the decision-makers in SME's. A more in-depth approach was required to obtain final factors that influence succession planning within an organisation. The results revealed that most familyowned businesses have no formal succession planning system in place. In addition, the reasons for the failure of successful succession planning were revealed, and that by implementing a formal process into the organisation, less trauma, confusion and damage in the company occurred when an inevitable key position became vacant.
\end{abstract}

Keywords: Corporate Culture; Family-Owned Businesses; Succession Planning

\section{INTRODUCTION}

South Africa is plagued with a high rate of unemployment due to a number of reasons, including a constant stream of immigrants flowing into the country. There is a high failure rate of the succession process and only one-third of these organisations move onto a second generation, and when one considers the third generation this figure dwindles down to only 10-15 percent. (Filser, Kraus and Mark, 2013:257).

SME's need to focus on succession planning, ensuring that they develop the human resources as well as talent management within the organisation, to ensure future succession to the next generation. Owners of small organisations need to focus on incorporating succession planning into their growth plans, to ensure the longevity of the organisation. Filser et al. (2013:260) mention interviews in which heirs felt pressurised about taking over the reins from their parents. Results showed that heirs usually made the decisions on their own and any resulting pressures relating to taking over the organisation came from the inheritors themselves. The authors also consider that further complications that may arise in succession planning are decisions being made by business owners to remain involved in the organisation.

Duh, Tominc and Rebermik (2009:257) state, that an organisation's growth is vital in the development of the economy as well as job creation and wealth. The authors mention, that one of the biggest problems facing family-owned businesses, is the transfer of ownership to the next generation of the family (Duh et al.,2009:250).

Another matter to be considered is whether this is, in fact, the best option for the organisation, or if it may be a better option to consider external candidates for successful succession planning. The implications of the organisation, not successfully being handed over to another generation has farreaching implications, to the economy of the country as well as the employment rate. It would be of benefit to attempt to uncover what the deciding factors are in succession planning of these firms and 
An Investigation into the Factors that Determine Successful Succession Planning in Small to MediumSized Family-Owned Businesses in Johannesburg, South Africa

whether these factors were efficient or not. If it can be determined what factors are inefficient, recommendations could perhaps be made to reduce or eliminate them.

The primary objective of the study is to determine the level of importance that succession planning enjoys, as well as determine the challenges associated with succession planning.

\section{LITERATURE REVIEW}

There is much emphasis placed on succession planning in large and corporate companies, but it is vital to assess if owners and managers of SME's consider the importance of careful succession planning in their organisations. It is in this regard that this research will focus on the factors affecting implementing successful succession planning in small and family-owned businesses, especially in South Africa. The research also comments on what factors have been found to be unique to familyowned businesses globally. It has been found that there are much more psychological and emotional influences that affect decisions that are made within the family business, and so these may influence the decisions concerning succession planning. Finally, the research refers to literature that focuses on the South African context. These are factors that are unique to the country and so influence decisions made in South Africa that may not be relevant to other family businesses globally.

South Africa only became a democratic country in 1994, when it emerged from an oppressive apartheid regime which resulted in unique challenges which are both social as well as economic. Prior to 1994 , the private and public sectors were always separate entities, with no government intervention and the directors' sole responsibility was to shareholders and profitability. It is only recently, that there has been a shift away from the interests of the shareholders and the recognition of a wider variety of interest such as employees, the general public, as well as the environment.

Ramlall (2012:273) states that there is an ongoing debate about whether large corporations have improved conditions by employing previously disadvantaged people in semi-skilled positions. There is much emphasis placed on succession planning in large and corporate companies, but it is vital to assess if owners and managers of SME's consider the importance of careful succession planning in their organisations. It is in this regards that this research will focus on the factors affecting implementing successful succession planning in small and family-owned businesses, especially in South Africa.

\subsection{Effective Succession Planning}

Succession planning involves a number of important considerations. Different authors focus on different factors:

Vitee (2016) emphasises the importance of succession planning, as it will ensure that individuals leading the next generation will be competent to manage the organisation through future challenges. The author notes that this will enable a smooth transition when there are any losses in leadership or management. It is important for the organisation to have good future leaders, to be able to identify these leaders at an early stage and be able to mentor and mould them to step effortlessly into a superior's position. Vitee (2016) observed that although it is important to combine succession planning with a new vision for the future, it is also necessary to not lose focus of the founders' vision that contributed to the growth of the organisation in the first instance.

Berman-Gorvine (2014:3) quotes Steve Hunt's interview with Bloomberg BNA, in which he states "Turnover isn't the enemy - preventable, unplanned turnover is." Staff leaving an organisation, whether voluntary or due to unexpected circumstances, is a given. It seems irresponsible to not plan for that eventuality. Hunt also notes that the way in which individuals are treated as potential successors can be a delicate process.

Although different authors have different aspects they choose to focus on, a common thread runs through all of the definitions. It is of vital importance for leaders to be identified and mentored throughout the human resources strategy and it is important for the succession plan to be fully supported from the top levels of the organisation.

\subsection{Causes of Failure of Succession Planning}

There are some factors that have been identified as being reasons for the failure of succession planning in organisations and they include: 
An Investigation into the Factors that Determine Successful Succession Planning in Small to MediumSized Family-Owned Businesses in Johannesburg, South Africa

\subsubsection{The Relation between Human Resources and Succession Planning}

According to Nel, Werner, Haasbroek, Poisat, Sono and Schultz (2010:555) the human resources department should be actively ensuring a steady stream of suitable successors for senior positions. Human resources managers can optimise the careers of individuals to suit the company's needs.

Berman-Gorvine (2014:4) noted that human resources become increasingly important within an organisation, identifying the candidates that will be suitable for succession, and also determining if they fit in within the organisation's culture. The authors once again, quote Steve Hunt's interview in which he states that there are many ways in which to implement succession planning, and that "it depends on the culture of the company". Succession planning is important to ensure the organisation has a constant supply of talent for unexpected events, but also to create stability within the company. It is also important to ensure that grooming successors are done at all levels and that lower level positions are not overlooked. As candidates move up the organisational level, a gap will be created that should be automatically filled by a new candidate that has been groomed for the position. There should be no positions left unattended at any time.

Tyler (2012:79) addresses the problem in organisations that "favouritism influences promotion". Tyler defines favouritism as "preferential treatment of an employee on the basis of factors that do not directly relate to the person's ability to perform his or her job function, such as the person's background or ideology, or the hiring manager's gut instincts". The author suggests that human resources have to be clear about the criteria and qualifications required, to avoid the issue of favouritism. There has to be identifiable parameters that each candidate should meet before they should be considered for a position. Succession planning hinges on the correct leaders taking over, who are able to lead the organisation successfully into the next generation.

\subsubsection{The Relation between Business Strategy and Succession Planning}

Nel et al. (2010:560) define business strategy as the plan used by the business, "which the top management adopts to be competitive, and to manage that particular business". The succession plan should be aligned with the business strategy, to achieve the same goals and give the organisation the competitive edge it needs.

\subsection{Methods of Succession Planning Within Organisations}

There are two methods of ensuring that the correct candidates are employed for management positions in the organisation, and are largely dependent on the strategic planning adopted by the organisation. Human resources can make use of both methods simultaneously for various positions, depending on which skills are required.

\subsubsection{Internal Recruiting}

Noe, Hollenbeck, Gerhart and Wright (2010:212) examine the fact that promote-from-within policies make it clear to individuals that there are opportunities for growth within the company. Identifying suitable candidates internally allows the organisation to invest in developing, training and mentoring, to take over leadership positions. This willingness to invest in employees leads to a highly motivating culture within the company and keeps labour turnover low.

\subsubsection{External Recruiting}

Berman-Gorvine (2014:5) state that "another purpose to succession planning is attracting talent from the outside". At times there may be no suitable candidate for the position internally, and external recruitment will be the only option. Candidates will be attracted to organisations that are perceived as rewarding and promoting deserving candidates to higher positions, they may also bring in new and fresh ideas to the company. Noe et al. (2010:215) note that external recruitment many strengthen an organisations position while weakening the opposition's.

Hough, Arthur, Thompson, Strickland and Gamble (2011:256) mention that the best organisations make use of both recruiting and retaining talent at the same time, as the objective is to make the workforce a strong resource. By using both external and internal recruiting within an organisation, the company can keep up morale within the company by investing in the existing workforce, but also encourage new ideas to create a more competitive organisation. 
An Investigation into the Factors that Determine Successful Succession Planning in Small to MediumSized Family-Owned Businesses in Johannesburg, South Africa

\subsection{Family-Owned Businesses}

Bigliardi and Dormino (2009:7) refer to the family business as "an enterprise controlled by members of a single family, in which both ownership and policy-making are dominated by members of an emotional kinship group that has experienced at least one generation transition". The authors note that this "emotional kinship" may result in fundamental differences between these businesses and other organisations in many ways, including the succession planning techniques used from one generation to another.

\subsubsection{Succession Planning in Family-Owned Businesses}

Filser et al. (2013:257) noted that worldwide, family-owned businesses have an enormous economic impact but that unfortunately, only one-third of these businesses are handed over successfully to a second generation and a mere $10-15 \%$ survive to the third generation. Much study seems to have been done on succession planning within large corporations but more attention is should be paid to what is lacking in the family organisations as far as succession planning is concerned. There clearly appears to be a significantly different approach to succession planning in family-owned businesses than in larger organisations.

Duh et al. (2009:258) note that in a family-owned business, according to the majority of studies, succession is usually caused by the owner's retirement. The other reasons for succession could be personal decisions, the competitive market changing, or life-changing incidents such as illness or divorce. It seems rare in these organisations, for the founder member to move on to other opportunities.

Laakkonen and Kaniskas (2011:981) noted that family businesses have "the advantage of kinship" which aids in trust and commitment within the business. This can be a source of conflict or of cooperation in the business.

Lussier and Sonfield (2010:417) suggest there are differences in management styles depending on the generation of the organisation, suggesting that the second or third generation organisation, is considered a more "professional" style of management, which included non-family managers. The authors note that the founder member is usually an entrepreneur with the necessary skills to create the business, whereas later generations need the skills to maintain and improve the area, and this may be attained by contracting non-family members into the organisation.

\subsection{Problems Associated with Family-Owned Businesses}

The problems associated with succession planning are the same globally, but the dynamics within a family business make the process of succession planning even more difficult. These need to be identified and addressed to ensure the organisation can be passed on from one generation to another.

Filser et al. (2013:265) observe that a positive succession process is dependent on the relationship between the parent and the child chosen as successor, and the decision of the owner to hand over to the successor is an important step but it may lead to conflict. The authors state that clear communication is essential, as well as power.

\subsubsection{Psychological Issues}

One of the greatest issues in family-owned companies seems to be psychological ones. Larger organisations may have systems and policies in place, such as a retirement age, or medical retirement, which takes out the emotive side of certain decisions.

\section{a) The Reluctant Owner}

Filser et al. (2013:258) state that literature has, to date, focused mainly on the factors related to the founding member's reluctance to plan for his/her succession for a number of purely psychological reasons, ranging from not wanting to relinquish control, or not having faith in the next generation. Most founding members put all their resources, time and effort into building their business and are sceptical of what to do with themselves if they retire. The authors comment that the only way to overcome these problems is through nurturing and mentoring the heirs to ensure the founder's drive and values are made clear and carried through to the next generation. 
An Investigation into the Factors that Determine Successful Succession Planning in Small to MediumSized Family-Owned Businesses in Johannesburg, South Africa

\section{b) The Reluctant Heir/Successor}

Laakkonen and Kansikas (2011:981) state, that the successor of the family business needs to be motivated, capable and willing to step into the owner's position. In some instances, the heir to the family business may not be interested, and it would be necessary to look for a non-family member successor either within or outside of the organisation. In other instances, the successor may be willing but feels incapable due to a lack of mentoring and training.

\section{c) Family Dynamics}

Morris, Allen, Kuratko and Brannon (2009:2) state that when a change in the company coincides with a change within the family, the transition in the organisation is even more stressful and may lead to dysfunction within the organisation. If succession has occurred due to the death of the CEO, this is not only devastating to the family but may affect the function of the business.

\subsubsection{Legal Issues}

Ip and Jacobs (2006:332) mention that there are various legal considerations that have to be borne in mind when a business has new ownership. The main issue is that each business entails different legal procedures as to how the business is transferred to a new owner.

\subsubsection{Financial Issues}

Morala (2009:40) mention that small businesses should have a "buy and sell agreement" in place if any partnerships are involved. In the case of a member dying, the shares of the organisation will automatically be transferred to the spouse or children. This will lead to disruptions as the heirs may be unwilling to participate and the partner will need to find funds to buy the shares, leading to more strain within the organisation. Human resource management can ensure the development of all staff within the organisation, but very few businesses are financially able to afford formal training and education for staff due to the associated high costs.

\subsubsection{Tax Issues}

Filser et al. (2013:257) also note that there is a burden of tax during the transfer of a family-owned firm, as this will include capital gains tax and/or inheritance tax. If the owner of the organisation does not have plans in place for the tax payments, heirs may end up putting a financial strain on the organisation by taking loans, or being forced to sell the organisation in order to pay the tax required.

\subsection{South African Context}

\subsubsection{Government Initiatives}

Ramlall (2012) mentions that the government decided against passing legislation forcing companies to take social responsibility, instead a number of laws were passed which indirectly get these organisations to take responsibility. These are mentioned below.

a) B.E.E.

Black Economic Empowerment (BEE) was introduced to encourage black ownership but this approach turned out to be too narrow, as it only benefited a few individuals. This was considered as being too narrow a definition, as it only focuses on a few individuals that would benefit, while the majority of disadvantaged people would not benefit.

\section{b) $B$-BBEE}

The introduction of Broad-Based Black Economic Empowerment (BBBEE or B-BBEE as written by the South African government), addressed this problem by encouraging the empowerment of black employees as well as the shareholders. Ramlall (2012:274) states that the main objective of this act is to "increase access to ownership, management positions, skills development, and supply chain opportunities, for historically disadvantaged South Africans". Although companies are not forced to comply, incentives are given by achieving a B-BBEE status. The status of the company will determine to what extent they can function in both the public and private sectors. The B-BBEE Act now binds the public and private sectors in that the private sector has to adhere to certain stipulations if they wish to do business with the public sector. 
An Investigation into the Factors that Determine Successful Succession Planning in Small to MediumSized Family-Owned Businesses in Johannesburg, South Africa

\section{c) The Success of B-BBEE}

The Acting Commissioner of Broad-Based Black Economic Empowerment (B-BBEE) Commission, (2017), Ms Zodwa Ntuli, referred to their review which revealed that the monitoring of transformation was not meticulously carried out and she recommends that B-BBEE not be arbitrarily applied. Measurements should be employed against the National Development Plan which aims to reduce inequality, unemployment and poverty and Ms Ntuli recommends the interrogation or company reports and spending patterns.

\subsubsection{The Impact of Legislation on Small Businesses}

Smith (2013) reports that two challenges arise for small businesses. Firstly, there seems to be a shortage of qualified and available empowerment partners. The second challenge is finding matching or similar cultures between the family business and the empowerment partner. The culture within family-owned businesses tends to be "self-driven, fearless, hands-on individuals who believe in themselves, in what needs to be done and are prepared to take risks".

Rossouw and van Vuuren (2010) mentions, "One cannot force those who own the assets upon which business functions to deploy them in a manner preferred by another partner." The motivations and benefits for a black-owned business compared to a partnership with a white-owned business are also unclear. Rossouw (2010) states that in her experience, many black business owners feel no need or advantage into entering into a partnership with a white business owner. The author notes that BEE is being driven by white business owners being forced into BEE deals, purely for survival and sustainability, without the co-operation of the empowerment partner.

\subsection{Implementing Succession Planning as a Business Process}

Hough et al. (2011:255) state that an essential part of successful strategy execution is the quality of the organisation's staff. Leading global companies screen candidates, not only on their knowledge, but on their people skills to assess if they can relate to clients and colleagues. The core concept "Adding to a company's talent base and building intellectual capital" is more important to good strategy execution than additional investments in plant equipment and capital projects.

Noe et al. (2010) tabulate the steps that an organisation should take in developing a succession plan as follows:

\subsubsection{The Importance of Leadership in Succession Planning}

Succession planning can be viewed as part of change planning as the organisation is planning, in advance, for the inevitable change in the human resources structure. For any effective change to occur with an organisation, it has to be coupled with leadership. The workforce will not willingly support any business plan if the leadership of the organisation does not show support. Leaders need to lead and show by example.

Nel et al. (2010:539) propose the following leadership approach when dealing with change in the organisation:

Develop the need to change: People only develop the need to change when it is created by management.

Develop a change vision: Top leaders must have a clear vision of where the organisation is headed.

Develop a communication strategy: Communication to staff about what to expect in the future is key.

Communicate the vision: People tend to panic when future plans are not communicated.

Get your work leaders informed: Communicating with different levels is important.

Get the transformation team together: The team needs to have the appropriate status and power to make them accepted in the workplace.

Do an organisational audit: The organisation needs to know what they have (all kinds of resources including human resources) before change can be planned.

Decide on the change process: The planned process needs to be communicated to everybody transformations take time. 
An Investigation into the Factors that Determine Successful Succession Planning in Small to MediumSized Family-Owned Businesses in Johannesburg, South Africa

Prepare the organisation and also the stakeholders: Managers at all levels need to be prepared as they need to support staff during the change.

Implement the changes: The various plans are now to be implemented.

Remove hindrances: Any hindrance should now come to light and should be removed and can include policies, structures and even employees.

Mainstreaming the changes: Performance management should be implemented to ensure that performance values have not dropped due to the change.

No plans or projects must be cast in stone: An organisation is an organic and changing structure and flexibility is always preferred.

These points can be useful in implementing succession planning, as it involves planning for a change in leadership and planning the change systematically can only be beneficial to the organisation.

\section{RESEARCH DESIGN AND METHODOLOGY}

For the purpose of this study, a qualitative approach was deemed appropriate. The researcher could obtain a deeper understanding of the psychology and rationale behind the decision-makers in SME's. A more in-depth approach is required to get to final factors that influence succession planning within an organisation. Given the size of the sample group, a qualitative approach gives more detail and understanding of why certain decisions are made. The data obtained is of personal opinions and experiences, this allows the researcher to ask more detailed questions to get to the answers required.

\subsection{Target Population}

The target population of the research were all small to medium-sized family businesses in Johannesburg. This is an enormous group and it was impossible to interview each company. For this reason, it was vital to isolate a sample population, on which to ground certain generalisations about the total population. It seems reasonable to choose a target population of ten different business owners and their succession planning theories, analysing these shows any discrepancies or if there seems to be a general trend toward making decisions. This research was based on a purposive sampling method, as the researcher needed to select participants that have similar characteristics such as:

- The business needs to be owned by a family member.

- The business must be based in Johannesburg.

- The business must be a small to medium-sized organisation.

This research used non-probability sampling using the purposive method. The sample group for this study consisted of ten business owners, in which family members are employed. In this research, questions were designed to focus mainly on succession planning in the participants' relevant organisations, factors that were in the way of succession planning being implemented and the necessary steps that could be considered essential in encouraging family-owned organisations to engage in the process of succession planning. All questions were asked in a manner in which eliminated as much bias as possible and any perceived ambiguities. Since the topic is considered sensitive, all participants were assured of complete confidentiality and anonymity.

\subsection{Limitations}

Due to the history of South African politics, family-owned businesses may not be a true reflection of the demographics of the country but it will, however, be a true reflection of the state of family-owned businesses at this present time. The research findings may vary and change if it is to be repeated in the future. The researcher avoided all forms of bias throughout the duration of the research.

\section{RESUltS AND DiscusSiONS}

In the sample group interviewed, $100 \%$ of the participants were the business owners or directors within family businesses, and European, speaking either English or Afrikaans. Only three of the participants were close to retirement age, also explaining the lack of succession planning. It would seem as if owners of the companies seem to couple succession planning with retirement. Only one participant was in a third generation family-owned business, two participants were in a second 
An Investigation into the Factors that Determine Successful Succession Planning in Small to MediumSized Family-Owned Businesses in Johannesburg, South Africa

generation business. The remaining participants were all founding members of the companies. What was of interest in the research, was that the second and third generation companies had a succession plan in place and a clear vision of where the company was heading in the future. It would seem that once a succession plan has been in place and worked, that the companies transition from one generation to the next is smoother and expected. The research was $60 \%$ in the manufacturing field and $20 \%$ engineering with a mere $10 \%$ falling into the service or retail sectors.

One of the questions asked in the study, concerned the annual turnover (in South African rand) as well as the number of employees in each company that participated in the research, in order to determine the extent to which the participants of the research did qualify as SME's. This evidence should emphasise the importance of considering the factors that are influencing family-owned businesses and the effect they have on the country's economy, as well as creating employment opportunities.

\subsection{Incorporating Succession Planning in Business Planning}

The research reflects, that most organisations, especially those with vision, are aware of the importance of succession but appear to have difficulty in developing formal procedures at aiming, developing, as well retaining, talent in the organisation. $25 \%$ of the owners interviewed, have no family heirs and as such would prefer to sell their company at a certain stage, making a profit on which they can retire. One participant's answer was simply that, "I have no succession plan and no interest to train an external recruit. I have no family interested and it is simpler to just sell." The other portion of the $25 \%$ do have family heirs, but they have their own careers and are not interested in taking over the family business. The remaining $75 \%$ of owners interviewed, are aware of the importance of succession planning, the majority of which do have children working within the company. The methods, plans and reasoning underlying the decisions made regarding succession planning determine the success or failure of the succession planning. Participant two noted, "There is no official succession plan in place as the shareholders are not close to retirement age, however, we are undertaking in-house training to ensure a successful overlap of responsibilities."

\subsection{Section B: The Causes of Failure of Succession Planning in Family Businesses}

The psychological aspect of the founding member, or the owner of a family-owned business, is one of the greatest attributes that set it apart from other organisations. Most owners have sacrificed much to make their dream come true, and so their emotional involvement can be seen as an attribute or a disadvantage. As discussed in the literature review, this may make an owner reluctant to much-needed change, ranging from retirement and allowing another to take over the helm to making detrimental financial decisions. The research however, has shown that this "pride" also may allow the organisation to overcome odds stacked against them, when they feel there is no other option.

\subsubsection{No Apparent Heir to Take Over}

This aspect is a large reason for companies having no succession plan in place. The participants may have children, but none that are willing to take over the next business, and in those particular cases seem to be more inclined to sell the business, rather than having a succession plan in place. The research reflects that only $20 \%$ of owners interviewed are prepared to be involved with succession planning, without apparent heirs. The other $30 \%$ with no apparent heirs, would prefer to sell the business at a later stage.

\subsubsection{Psychological Reasoning}

Personal differences and ego may lead to incorrect or detrimental decisions being made. Participant six noted that, "We have no official succession plan in place at the moment although I would like to leave it to my children, to fulfil my late husband's dream." This reasoning would not usually apply to an organisation. Participant seven had potential and willing heirs to the business but stated, "I have no succession plan in place. I am concerned about labour unrest and the safety of my family."

\subsubsection{Political and Economic Decisions Government Interventions}

$100 \%$ of the participants of the research were motivated by government policy in one way or another. For some family-owned companies, especially if the family was employed, it was because of the high rate of employment and because of BEE policies, that succession planning was being considered. 
Most of the participants considered this as ensuring some kind of future for their children. Participant four said the main reason for their succession plan, involving their children was, "The high unemployment rate. The company gives a good or better income for the children, and there are not many opportunities in this country anymore, so we need to make provisions for our children."

Participant five has been a statistic of crime and her children have emigrated. "Our business has been in the family for sixty years and we have no interest in handing over the reins to anyone. Our intention is to keep the business until we can find a suitable buyer."

In the research, there is a definite overlap between psychological reasoning and political interventions. Even the most negative of participants, considered that in the current economic state of South Africa, that the business would at least offer their children some kind of job or financial security in the future.

\subsection{Section C: Measures for Encouraging Succession Planning in Family-Owned Companies}

In the research conducted, $10 \%$ of the participants were in third generation companies, $30 \%$ were in the second generation and the remaining $60 \%$ were first generation companies (the founders). The participants from second and third generation companies were more familiar with the succession process and were in the process of mentoring and training the next generation, as well as identifying and recognising key roles that would be vital to the organisation.

\subsubsection{Owner Support}

Every participant in the research agreed that in a family-owned business, every single decision made in the organisation can only work if employees are aware of the management and owner's support. In SME's there is a more hands-on approach by owners when it comes to all aspects of the business.

\section{CONCLUSION \& RECOMMENDATIONS}

For family businesses to be successfully transferred from one generation to the next, it is of vital importance to adopt the appropriate planning process modes and tweak and adjust the model to fit in with the appropriate organisation. The research revealed, that when asked about succession planning, the immediate thought is of the succession of the owner, not much thought is given to succession planning throughout the business as a whole, and at all levels.

The recommendations were based on the conclusions from the findings.

\subsection{Support Systems}

The study established the importance that family-owned businesses have on the economy through the creation of jobs, supporting large households, improving the livelihoods of families and contributing to the infrastructure of the country through taxes. It would seem logical that an important sector of the economy receives more support from the government to ensure the survival of the company. Institutions may focus on providing adequate training for owners on how to best implement strategies that would work for these companies.

\subsection{Developing a Succession Plan}

Noe et al (2010:448) suggest the steps that an organisation should take in developing a succession plan as follows. Each point raised has been linked to this research:

Step 1: Identify key positions: It is recommended to start considering the retirement forecast of existing employees, what positions are currently vacant or are due to be vacant (e.g. maternity leave or resignation), which positions are highly specialised as well as the turnover rate of the staff within the organisation. The organisation then has to consider the impact that vacant position would have on the organisation not achieving its goals, which positions deal directly with the public, which jobs require a certain amount of skill or expertise that nobody else can fulfil that function? Depending on how specialised the organisation is, could there be a future deficit in the labour market? Finally, is the company planning on expanding and are there enough employees to fill the positions?

Step 2: Identifying candidates: In a family-owned business, the first thought is of the heir, but it is of vital importance to determine whether the heir is interested in taking over. The same transparency would apply to the entire company, finding out which employees are interested in career 
An Investigation into the Factors that Determine Successful Succession Planning in Small to MediumSized Family-Owned Businesses in Johannesburg, South Africa

advancement, discussing career goals and career interests. Some individuals may be stuck in a field they have no passion for and would prefer to move in a different direction. Once it has been determined who the willing candidates are, further selection processes such as interviews or simulating work exercises can be performed and reviewed.

Step 3: Develop standards to evaluate positions: Once the key positions in step one have been identified, it is necessary to decide on the criteria needed for each position. Interview each person performing each position, finding out what qualities and experience is considered essential to carry out that task. This is an extremely important step to ensure that the correct baseline and job description is set in place, against which new candidates can be measured.

Step 4: Determine how the employee will be measured: This step may become cumbersome in smaller organisations, but a template can be set out for each position, listing the competencies required, the targets that are expected to be met, compliments or complaints from clients or suppliers A supervisor can annually or bi-annually rate the employee on each criterion, giving an indication of whether the individual is coping with what is expected or if more training and aid is required in developing that skill.

Step 5: Develop the succession planning review: It is always important to get the co-operation of all staff and supervisors, to ensure that they understand and are willing to partake in the succession planning process on a regular basis. No plan will ever succeed without staff support, especially in SME's.

Step 6: Training and developing: Once the candidates have been identified, and it has been determined that they are competent as well as interested in training for key positions, the organisation has to ensure that opportunities to develop and learn are granted. Depending on the level of expertise required, as well as the training facilities available in the country, training can start off with in-house training, having the person in the key position, and transferring knowledge and skills to the participant. Other positions may require short computer courses and more advanced learning, which each individual company can decide on how to compensate. The South African government charges each company a compulsory annual skills-development fee, which can be claimed back by the company if staff are sent for training. This is a good incentive to get willing and competent people trained and compensated through the government, as well as by having motivated and loyal staff.

Step 7: Determine what feedback is provided to the employees: Measuring performance criteria by a supervisor can be sensitive and subject to the employee. Care must be taken of how information is handled in the organisation. If there are shortcomings, there may be valid reasons and simple ways of resolving them. It is also of utmost importance to communicate the expectations of the organisation and help develop shortfalls that are identified.

Step 8: Evaluate the succession plan: Each organisation is unique, and in family-owned businesses, processes tend to be more informal than larger organisations. Certain steps may seem cumbersome and unnecessary and the plan can be modified to suit the company's needs. Having said that, the formal succession plan may be modified but it is of vital importance for the formal succession process model to be in place.

\subsubsection{Treat Succession Planning as a Business Process}

Succession planning should be viewed as change planning, as it is inevitable and for any change to occur successfully, it has to be coupled with strong leadership. A business strategy is a set of goals and objectives set out by the organisation to give it a competitive edge over the competition. The succession plan should be aligned with this strategy and continually adapted and changed as the competitive nature of the organisation changes. An organisation cannot be competitive if there is no plan to keep its talent and staff up to date with the ever-changing trends in the business environment.

\subsection{Recommendations for Further Study}

Family-owned businesses are faced with different obstacles compared to large organisations, the main obstacles being psychological as well as financial obstructions. Having formal processes in place for succession planning should alleviate some of the psychological concerns. Knowing that with some effort, a formal process will eventually ensure that key roles are always fulfilled, staff will be satisfied 
An Investigation into the Factors that Determine Successful Succession Planning in Small to MediumSized Family-Owned Businesses in Johannesburg, South Africa

and heirs (if there are any) should have a well-structured and secure business to take into a new direction. Owners may also be more comfortable with handing over to an external candidate, in the knowledge that processes are being followed. The sample size in this study was small, and it may be beneficial to consider different industry sectors to compare and contrast the challenges that are being faced by family-owned businesses.

Both literature and primary reviews established that family-owned businesses play a vital role in influencing the livelihoods and survival of many South African households through job creation and skills development. The businesses also contributed taxes to upgrade the infrastructure in the industrial sectors. Studies revealed that the survival of the family business is hindered by psychological and financial reasons, crime, government support, expensive training and development costs. Small businesses simply do not have the funds or resources to implement business process and strategies.

The literature and this study revealed that the government initiatives can be beneficial as well as destructive to succession planning. Improved support systems, and the training of owners of businesses on how to put strategies in place and how to implement them can be of great benefit. This will be of benefit to both the owner, the employees and finally, the economy.

\section{REFERENCES}

[1] B-BBEE Commission (2017). Accelerating the work of the B-BBEE Commission is of imperative importance. [Online] Available: https://www.bbbeecommission.co.za/accelerating-the-work-of-the-bbbee-commission-is-of-imperative-priority/; [Accessed: 12 September 2017].

[2] Berman-Gorvine, M. (2014). Succession Planning Requires Forethought, Sensitivity. HR Focus, 19 (2). 36.

[3] Bigliardi, B. \&Dormio, A.I. (2009). Successful generational changes in family business. Measuring Business Excellence, 12(2):44-50.

[4] Duh, M., Tominc, P. \&Rebernik, M. (2009). Growth ambitions and successionsolutions in family businesses. Journal of Small Business and EnterpriseDevelopment, 16(2): 256-269.

[5] Filser, M., Kraus, S. \& Mark, S. (2013). Psychological aspects of succession infamily business management. Management Research Review. 36(3). 256-277.

[6] Hough, J., Arthur, A., Thompson, J.R., Strickland, A.J. \& Gamble, J.E. (2011). Crafting and executing Strategy. Creating sustainable high performance in SouthAfrica: Text, Readings and cases. $2^{\text {nd }}$ Edition. Mc-Graw-Hill.

[7] Ip, B. \& Jacobs, G. (2006). Business succession planning: a review of the evidence. Journal of Small Business and Enterprise Development. 12(3) 326-350.

[8] Laakkonen, A. \&Kansikas, J. (2011). Evolutionary selection and variation in family businesses. Management Research Review.34(9):980-995.

[9] Lussier, R.N., \&Sonfield, M.C. (2010). A six - country study of first, second and third class generation family business. International Journal of Entrepreneurial Behaviour and Research, 16(5):414-436.

[10] Morala, S. 2009. Entrepreneurs have to plan for succession. Finweek: 40. 2 July.

[11] Morris, M.H., Allen, J.A., Kuratko, D.F. \& Brannon, D. (2010). Experiencing family business creation: differences between founders, nonfamily managers, and founders of nonfamily firms. Baylor University. [Online] Entrepreneurship Theory and Practice. Available: https://www.effectuation.org/wp-content/ uploads/2017/06/Morris_et_al-2010-Entrepreneurship_Theory_and_Practice-1.pdf; [Accessed: 10 May 2017].

[12] Nel, P.S., Werner, A., Haasbroek, G. D., Poisat, P., Sono, T. \& Schultz, H.B. (2010). Human resource management. $7^{\text {th }}$ ed. Oxford University Press Southern Africa.

[13] Noe, R.A., Hollenbeck, J.R., Gerhart, B. \& Wright, P.M. (2010). Human resource management. Gaining a competitive advantage. $7^{\text {th }}$ Ed.Irwin. NY: McGraw-Hill.

[14] Ramlall, S. (2012). Corporate social responsibility in post-apartheid South Africa. Social Responsibilty Journal, 8(2): 270-288.

[15] Rossouw, D. \& Van Vuuren, L. (2010). Business ethics. Cape Town: Republic of South Africa, Oxford University Press Southern Africa.

[16] Smith, T. \& Barrett, R. (2014). "Informal e-learning: the case of small business owners", Education + Training, Vol. 56 Issue: 2/3, pp.219-232, https://doi.org/10.1108/ET-03-2013-0047 
An Investigation into the Factors that Determine Successful Succession Planning in Small to MediumSized Family-Owned Businesses in Johannesburg, South Africa

[17] Tyler, K. (2012). Undeserved Promotions. HR Magazine: 79, June. [Online] Available: http://www.shrm .org/hrmagazine/0612Tyler; [Accessed: 12 August 2016].

[18] Vitee, K.2016. Succession planning: A strategy for your business' future success. [Online] Available: http://www.smesouthafrica.co.za; [Accessed: $26^{\text {th }}$ August 2016].

Citation: Suzette Claase, Dr Rishaad Ebrahim. “ An Investigation into the Factors that Determine Successful Succession Planning in Small to Medium-Sized Family-Owned Businesses in Johannesburg, South Africa" International Journal of Managerial Studies and Research (IJMSR), vol 7, no. 1, 2019, pp. 39-50. doi: http://dx.doi.org/10.20431/2349-0349.0701005.

Copyright: (C) 2019 Authors. This is an open-access article distributed under the terms of the Creative Commons Attribution License, which permits unrestricted use, distribution, and reproduction in any medium, provided the original author and source are credited. 